\title{
Non-Invasive Assessment of Pulmonary Vasculopathy
}

\author{
Ines Ponz ${ }^{1}$, Jorge Nuche ${ }^{1,2,3,4}$, Violeta Sanchez Sanchez ${ }^{1}$, Javier Sanchez-Gonzalez ${ }^{2,5}$, \\ Zorba Blazquez-Bermejo ${ }^{1}$ (D) Pedro Caravaca Perez ${ }^{1}$ (D), Maria Dolores Garcia-Cosio Carmena ${ }^{1}$, \\ Javier S. de Juan Baguda ${ }^{1}$, Adriana Rodríguez Chaverri ${ }^{1}$, Fernando Sarnago Cebada ${ }^{1}$, \\ Fernando Arribas Ynsaurriaga ${ }^{1,3,4}$, Borja Ibañez ${ }^{2,3,6}$ and Juan F. Delgado Jiménez $1,3,4, *$ (D)
}

1 Cardiology Department University Hospital 12 de Octubre, Instituto de Investigación Sanitaria Hospital 12 de Octubre (imas12), 28041 Madrid, Spain; ines.ponz@salud.madrid.org (I.P.); jorge.nuche@salud.madrid.org (J.N.); vssanchez@salud.madrid.org (V.S.S.); zorba.blazquez@salud.madrid.org (Z.B.-B.); pedrojoaquin.caravaca@salud.madrid.org (P.C.P.); mariadolores.garcia-cosio@salud.madrid.org (M.D.G.-C.C.); javier.juan@salud.madrid.org (J.S.d.J.B.); adriana.rodriguez@salud.madrid.org (A.R.C.); fernando.sarnago@salud.madrid.org (F.S.C.); fernando.arribas@salud.madrid.org (F.A.Y.)

2 Centro Nacional de Investigaciones Cardiovasculares Carlos III, 28029 Madrid, Spain; javier.sanchez.gonzalez@philips.com (J.S.-G.); bibanez@cnic.es (B.I.)

3 Centro de Investigación Biomédica En Red Cardiovascular (CIBERCV), 28029 Madrid, Spain

4 Facultad de Medicina, Universidad Complutense de Madrid, 28040 Madrid, Spain

5 Philips Healthcare, 28050 Madrid, Spain

6 IIS-Fundación Jiménez Díaz Hospital, 28040 Madrid, Spain

* Correspondence: juan.delgado@salud.madrid.org

Citation: Ponz, I.; Nuche, J.;

Sanchez Sanchez, V.; Sanchez-Gonzalez, J.; Blazquez-Bermejo, Z.; Caravaca

Perez, P.; Garcia-Cosio Carmena, M.D.; de Juan Baguda, J.S.; Chaverri, A.R.; Sarnago Cebada, F.; et al. Non-Invasive Assessment of Pulmonary Vasculopathy. Hearts 2021, 2,5-14. https://doi.org/ 10.3390/hearts2010002

Received: 2 December 2020 Accepted: 31 December 2020 Published: 5 January 2021

Publisher's Note: MDPI stays neutral with regard to jurisdictional clai$\mathrm{ms}$ in published maps and institutional affiliations.

Copyright: (C) 2021 by the authors. Licensee MDPI, Basel, Switzerland. This article is an open access article distributed under the terms and conditions of the Creative Commons Attribution (CC BY) license (https:// creativecommons.org/licenses/by/ $4.0 /)$.

\begin{abstract}
Right heart catheterization remains necessary for the diagnosis of pulmonary hypertension and, therefore, for the prognostic evaluation of patients with chronic heart failure. The non-invaSive Assessment of Pulmonary vasculoPathy in Heart failure (SAPPHIRE) study was designed to assess the feasibility and prognostic relevance of a non-invasive evaluation of the pulmonary artery vasculature in patients with heart failure and pulmonary hypertension. Patients will undergo a right heart catheterization, cardiac resonance imaging, and a pulmonary function test in order to identify structural and functional parameters allowing the identification of combined pre- and postcapillary pulmonary hypertension, and correlate these findings with the hemodynamic data.
\end{abstract}

Keywords: heart failure; pulmonary hypertension; cardiovascular magnetic resonance; right heart catheterization

\section{Introduction}

Pulmonary hypertension (PH) is a common complication of chronic heart failure (HF) associated with worse outcomes and increased mortality [1]. Its presence is a marker of poor prognosis in patients with HF [2,3]. It begins as a passive process due to congestion as a result of both systolic and diastolic left ventricular dysfunction. Chronically elevated pulmonary venous pressures induce structural changes in the pulmonary vasculature, which may become irreversible, increasing pulmonary vascular resistance (PVR) and the risk of right ventricular failure [4].

Currently, an invasive approach through right heart catheterization (RHC) remains necessary for the diagnosis and classification of $\mathrm{PH}$, as well as to determine its reversibility. Therefore, the interest in alternative, non-invasive diagnostic tools in the assessment of patients with $\mathrm{PH}$ is increasing.

Magnetic resonance imaging (MRI) has emerged as the gold standard for the evaluation of tissue characterization and of ventricular systolic function, especially of the right ventricle. The use of MRI is broadly extended in pulmonary arterial hypertension (PAH). Several studies have demonstrated a good correlation between different MRI findings and PAH severity, and they have thus been established as prognostic predictors [5-9]. 
In this field, perfusion or four-dimensional (4D) flow sequences have been shown to be promising techniques in the evaluation of flow patterns and vascular compliance among PAH patients [10]. However, the value of these techniques in the assessment of patients with postcapillary $\mathrm{PH}$ evaluation has not yet been established.

Structural changes in pulmonary vasculature have been shown to induce a reduction in the diffusing capacity of the lungs for carbon monoxide (DLCO). In patients with severe precapillary PH, reduced DLCO is as a marker for poor prognosis [11]. Furthermore, DLCO $<45 \%$ has been shown to be associated with an increased mortality at 3 years in patients with $\mathrm{PH}$ and HF with preserved ejection fraction (HFpEF) [12].

Our aim is to define the rationale and design of the SAPPHIRE study (non-invaSive Assessment of Pulmonary vasculoPathy in Heart faIluRE). This study was designed to perform a structural and functional evaluation of the pulmonary artery vasculature through MRI in patients with HF and PH in order to determine if there is a relationship with the degree and type of $\mathrm{PH}$ defined by hemodynamic criteria.

\section{Methods}

\subsection{Study Endpoints}

This study is based on the hypothesis that MRI and pulmonary functional test (PFT) parameters may help to identify those HF patients who have developed pulmonary vascular remodeling. This could be translated in fewer indications of invasive pulmonary hemodynamics evaluation among these patients.

Our main objective is to identify MRI and PFT parameters allowing the identification of patients with established pulmonary vasculopathy. Specifically, in patients with combined $\mathrm{PH}$, when compared with those with isolated postcapillary $\mathrm{PH}$, we expect to find the following:

- A reduction of pulmonary peak and mean systolic velocity, peak flow, stroke volume, and wall shear stress, with an increase in pulmonary artery pulse-wave velocity.

- An increased stiffness of the pulmonary arteries, with a decreased pulsatility.

- A lower DLCO.

Additionally, we aim to (1) explore the correlation of non-invasive parameters with the hemodynamic parameters obtained by RHC and (2) identify prognostic factors for HF outcomes.

\subsection{Design}

This a pilot study, single-center, prospective and observational, including patients with $\mathrm{PH}$ secondary to left heart disease. It is designed to perform a non-invasive assessment of structural and functional changes in the pulmonary artery vasculature in order to identify the presence of established pulmonary vasculopathy, defined as a combined $\mathrm{PH}$.

The study protocol and written informed consent form were reviewed and approved by the Institutional Ethics Committee of the University Hospital 12 de Octubre and of the Spanish National Cardiovascular for Cardiovascular Research (CNIC).

\subsection{Patient Selection and Follow-Up}

Inclusion and exclusion criteria are listed in Table 1. Patients will be enrolled in cases of symptomatic chronic HF and PH confirmed by RHC. This includes either patients with advanced HF or patients with chronic HF with reduced, mid-range, or preserved ejection fraction, following guidelines' definitions [13], at least six months from the beginning of symptoms. PH different from World Health Organization (WHO) group 2 will be excluded. All patients are under follow-up in the Heart Failure Unit of the University Hospital 12 de Octubre and may be considered for inclusion either after visit to the HF clinic or after a hospitalization due to HF decompensation. 
Table 1. Inclusion and exclusion criteria.

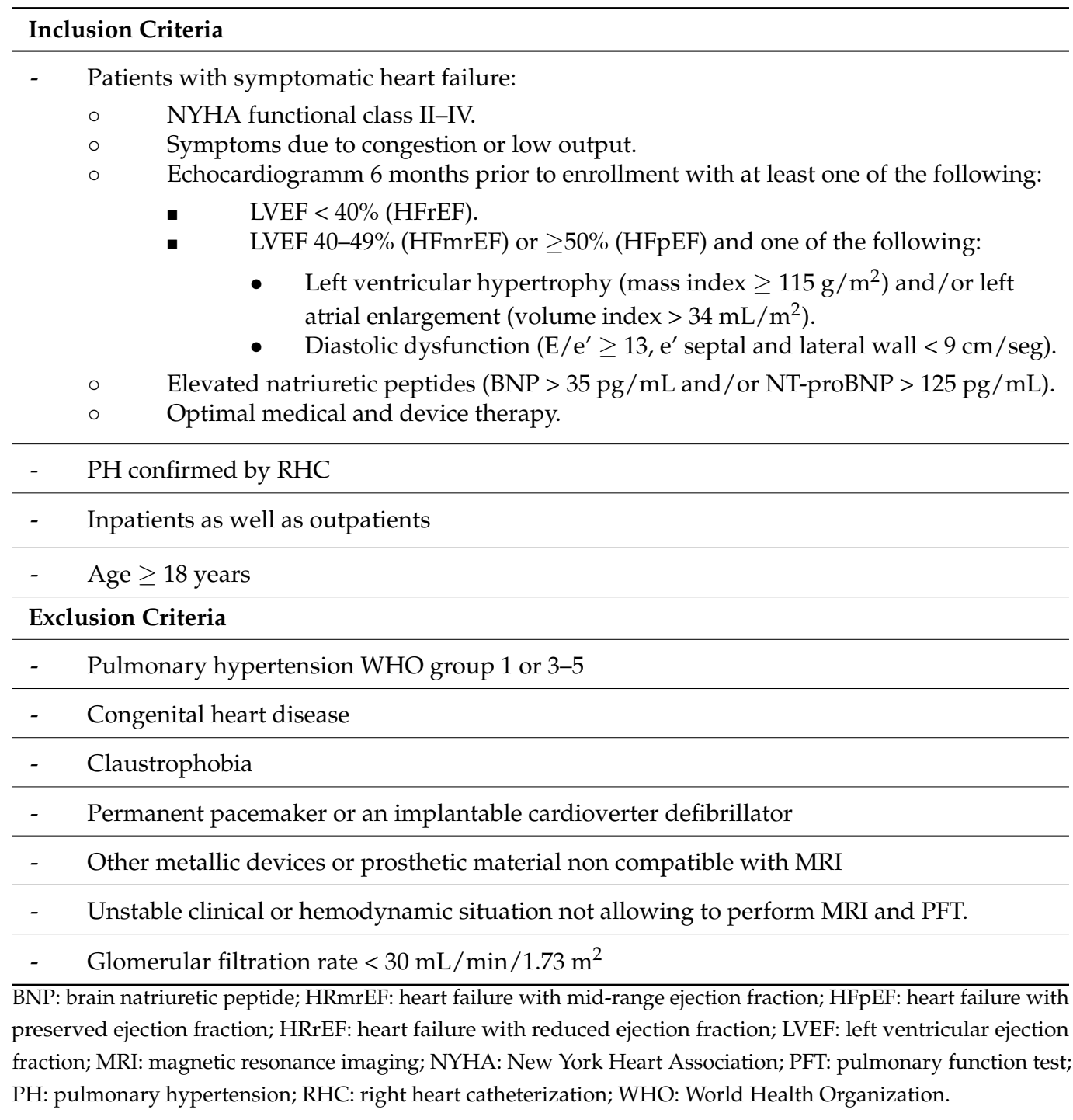

During screening, eligibility requirements will be assessed and confirmed. Written informed consent will be obtained from all participants of the study. Patients eligible for the study will undergo an RHC to confirm PH, when suspected. The RHC will be performed in a stable clinical condition. Patients screened during a HF decompensation will require treatment optimization prior to enrollment. Depending on the hemodynamic parameters, patients will be grouped as isolated postcapillary PH or combined pre- and postcapillary $\mathrm{PH}$, according to the current hemodynamic definition [14] (Table 2).

Table 2. Definition of pulmonary hypertension.

\begin{tabular}{|c|c|c|c|}
\hline \multicolumn{2}{|c|}{ Pulmonary Hypertension } & \multicolumn{2}{|c|}{ Definition } \\
\hline \multicolumn{2}{|l|}{$\mathrm{PH}$} & \multicolumn{2}{|c|}{$\mathrm{MPAP} \geq 25 \mathrm{mmHg}$} \\
\hline \multicolumn{2}{|c|}{$\mathrm{PH}$ due to left heart disease } & \multicolumn{2}{|c|}{$\mathrm{MPAP} \geq 25 \mathrm{mmHg}$ and $\mathrm{PWCP}>15 \mathrm{mmHg}$} \\
\hline \multirow{2}{*}{$\begin{array}{r}-\quad \mathrm{C} \\
-\quad \\
0 \\
0\end{array}$} & $\begin{array}{l}\text { d postcapillary } \mathrm{PH} \\
\text { ined pre- and postcapillary } \mathrm{PH}\end{array}$ & $\begin{array}{ll}- & \mathrm{D} \\
- & \mathrm{D}\end{array}$ & $\begin{array}{l}=7 \mathrm{mmHg} \text { and } \mathrm{PVR} \leq 3 \mathrm{WU} \\
\geq 7 \mathrm{mmHg} \text { and PVR }>3 \mathrm{WU}\end{array}$ \\
\hline & $\begin{array}{l}\text { Reversible } \\
\text { Irreversible }\end{array}$ & 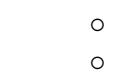 & $\begin{array}{l}\mathrm{PVR} \leq 3 \mathrm{WU} \text { with vasodilators } \\
\text { PVR }>3 \mathrm{WU} \text { after vasodilators }\end{array}$ \\
\hline
\end{tabular}

DPG: diastolic pulmonary gradient; MPAP: mean pulmonary artery pressure; PCWP: pulmonary capillary wedge pressure; PH: pulmonary hypertension; PVR: pulmonary vascular resistance; WU: Wood unit. 
Enrollment started in March 2018 and will last 24 months. Follow-up will last one year after enrollment. Major outcomes include readmission for HF and death.

\subsection{Pulmonary Hypertension Definition and Hemodynamic Evaluation}

According to the guidelines in force at the start of the recruitment phase [14], $\mathrm{PH}$ due to HF was defined as a mean pulmonary artery pressure (MPAP) $\geq 25 \mathrm{mmHg}$ with a pulmonary capillary wedge pressure (PCWP) $>15 \mathrm{mmHg}$, measured at end-expiration and at the beginning of the electric QRS [15] (Table 2). Thus, a MPAP $<25 \mathrm{mmHg}$ and/or a PCWP $\leq 15 \mathrm{mmHg}$ excludes $\mathrm{PH}$ as a result of left heart disease (WHO group 2). Isolated postcapillary $\mathrm{PH}$ is defined by a diastolic pulmonary gradient (DPG) $<7 \mathrm{mmHg}$ and $\mathrm{PVR} \leq 3$ Woods unit (WU). On the contrary, a DPG $\geq 7 \mathrm{mmHg}$ with PVR $>3$ WU indicates the presence of a combined pre- and postcapillary $\mathrm{PH}$.

Hemodynamic evaluation will be performed after treatment optimization with diuretics, inotropes, and/or pulmonary vasodilators, following clinical parameters, and always before MRI (Figure 1). In patients considered for heart transplantation or LVAD who have combined $\mathrm{PH}$, pulmonary vasodilator testing will be performed in order to assess the reversibility of the precapillary component (reduction of PVR $\leq 3$ ). In the case of non-response to vasodilators, the precapillary component of $\mathrm{PH}$ is fixed and irreversible, and a formal contraindication for heart transplantation.

In December 2018, an update of the hemodynamic definition and clinical classification of $\mathrm{PH}$ was published [16]. In this document, the 6th World Symposium on PH Task Force proposed a MPAP cut-off value of $>20 \mathrm{mmHg}$ in order to define $\mathrm{PH}$, maintaining a PVR $\geq 3 \mathrm{WU}$ as the definition of all forms of pre-capillary PH. In our study, this change in the definition of PH will be taken into account for patients' selection and data analysis. Thus, patients with a MPAP of $21-24 \mathrm{mmHg}$ will be included as part of the control group.

\subsection{Magnetic Resonance Imaging}

In the first $48 \mathrm{~h}$ after hemodynamic confirmation of $\mathrm{PH}$ diagnosis, all patients will undergo cardiac MRI at CNIC facilities. The studies will be performed on a 3T wide bore magnet Elition Xwhole-body scanner (Philips Healthcare, Best, The Netherlands) equipped with a 28-element phased-array cardiac coil. The acquisition protocol will be develop as follows:

- Standard segmented cine steady-state free-precession sequence (repetition time/echo time/flip angle $\left.(\mathrm{TR} / \mathrm{TE} / \alpha)=2.7 \mathrm{~ms} / 1.35 \mathrm{~ms} / 40^{\circ}\right)$ to provide high-quality anatomical references to evaluate ventricular mass, volume, thickness, and ejection fraction. Field of view (FOV) of $320 \times 320 \mathrm{~mm}$, slice thickness of $8 \mathrm{~mm}$ with no gaps, and in plane resolution of $1.8 \times 1.8 \mathrm{~mm}^{2}$ and 30 acquired cardiac phases.

- $\quad$ T1 (modified look-locker inversion recovery (MOLLI)) pre- and post-contrast (15 min after gadolinium injection) sequences based on a 5(3)3 scheme using a single shot steady-state free precession readout sequence (TR/TE/Flip angle $=2.1 \mathrm{~ms} / 1.05 \mathrm{~ms} / 35^{\circ}$ ) with an in-plane acquisition resolution of $1.5 \times 1.8 \mathrm{~mm}^{2}$ and an $8 \mathrm{~mm}$ slice thickness. These sequences will allow a quantitative evaluation of myocardial fibrosis and extracellular volume.

- Lung perfusion will be acquired using dynamic multi-slice acquisition using saturation recovery spoiled turbo field echo sequence during the first pass of contrast injection. Image resolution of the sequence will be $4 \times 4$ in plane resolution and 25 slices with a slice thickness of $10 \mathrm{~mm}$ and no gap between slices covering both lungs. Image volume will be acquired in coronal orientation to allow a higher parallel acceleration factor in the left-right direction (SENSE factor of 2.2), allowing to acquire a new imaging volume every $2.2 \mathrm{~s}$. Saturation delay time was adjusted to improve the signal intensity to contrast concentration $(100 \mathrm{~ms})$. The injection rate will be $3 \mathrm{~mL} / \mathrm{s}$ to avoid strong $\mathrm{T}^{*}$ effects during contrast administration.

- Late gadolinium enhancement sequence: performed 10 to $15 \mathrm{~min}$ after intravenous administration of $0.20 \mathrm{mmol}$ of gadopentetate dimeglumine contrast agent per $\mathrm{kg}$ of 
body weight (30) using a 2D inversion-recovery spoiled turbo field echo (IR-T1TFE) sequence with the following parameters: FOV of $320 \times 320 \mathrm{~mm}$, with in plane resolution of $1.6 \times 1.6 \mathrm{~mm}^{2}$, end-diastolic acquisition, thickness of $8 \mathrm{~mm}$ with no gap, TR $5.6 \mathrm{~ms}$, TE $2.8 \mathrm{~ms}$, inversion delay time will be optimized to null normal myocardium, and 2 number of excitations. The same sequence will be acquired in a short axis with as many slices as required to cover the entire cardiac muscle without a gap between slices and one slice in 2, 3, and 4 chambers views.

- Four-dimensional flow will be acquired using a 3D spoiled turbo field echo sequence $\left(\mathrm{TR} / \mathrm{TE} / \alpha=3.6 \mathrm{~ms} / 2.2 \mathrm{~ms} / 7^{\circ}\right)$ with isotropic resolution of $2.5 \times 2.5 \times 2.5 \mathrm{~mm}^{3}$ and 20 acquired cardiac phases covering an imaging volume of $320 \times 300 \times 300 \mathrm{~mm}^{3}$ (cranial-caudal, left-right (LR), and anterior-posterior (AP) direction, respectively). Images were acquired in three velocity encoding directions and the maximum velocity was adjusted according to the maximum velocity. A parallel acceleration factor of 5.7 (1.9 in AP and 3 in LR direction, respectively) will be applied to reduce the total acquisition time.

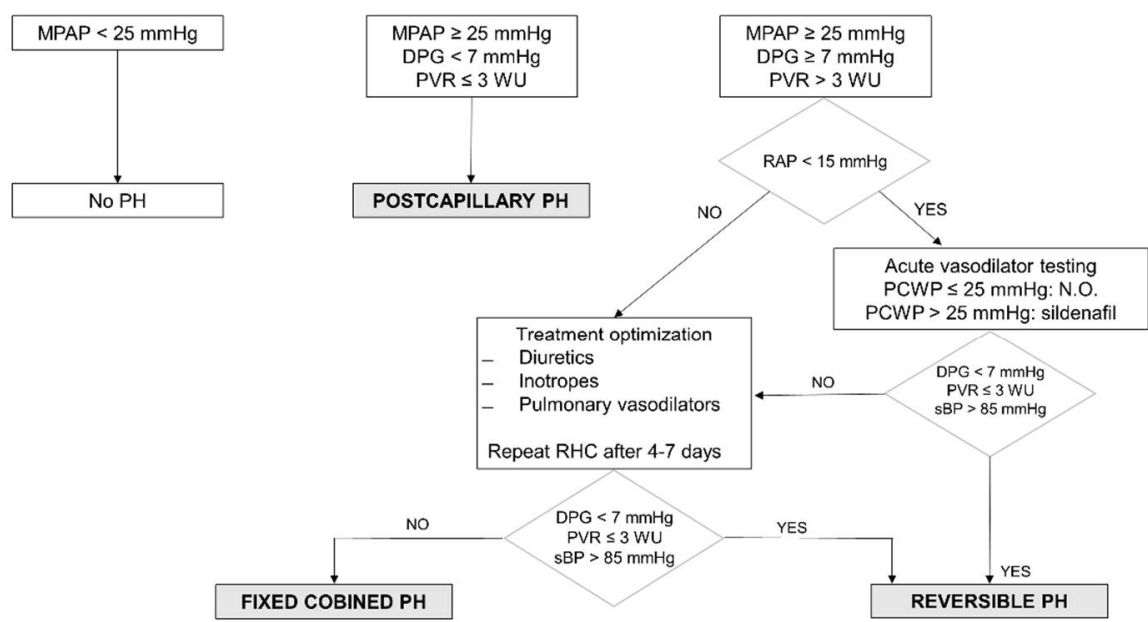

Figure 1. Hemodynamic assessment of pulmonary hypertension. Hemodynamic evaluation of PH, assessed by RHC. Postcapillary PH is defined as a DPG $<7 \mathrm{mmHg}$ and PVR $\leq 3 \mathrm{WU}$. A DPG $\geq 7 \mathrm{mmHg}$ with PVR $>3 \mathrm{WU}$ indicates the presence of a combined pre- and postcapillary $\mathrm{PH}$, which may be reversible in the case of a reduction of PVR $\leq 3 \mathrm{WU}$ after acute vasodilator testing. In cases of non-response to vasodilators or the presence of high right ventricular filling pressures, treatment optimization is required with diuretics, inotropes, and/or pulmonary vasodilators, before a hemodynamic reevaluation is performed after 4-7 days. The absence of response to treatment confirms the presence of a fixed combined PH. DPG: diastolic pulmonary gradient; MPAP: mean pulmonary artery pressure; N.O.: nitric oxide; PCWP: pulmonary capillary wedge pressure; PH: pulmonary hypertension; PVR: pulmonary vascular resistance; RAP: right atrial pressure; RHC: right heart catheterization; sBP: systolic blood pressure.

\subsection{Study Organization}

After confirmation of $\mathrm{PH}$, patients will be submitted to cardiac MRI and PFT with DLCO determination, within the first $48 \mathrm{~h}$ after RHC. Clinical and hemodynamic assessment, study enrollment, and PFT will be performed at University Hospital 12 de Octubre. MRI studies will be performed at the CNIC facilities. Patients' selection and study organization are summarized in Figure 2. 


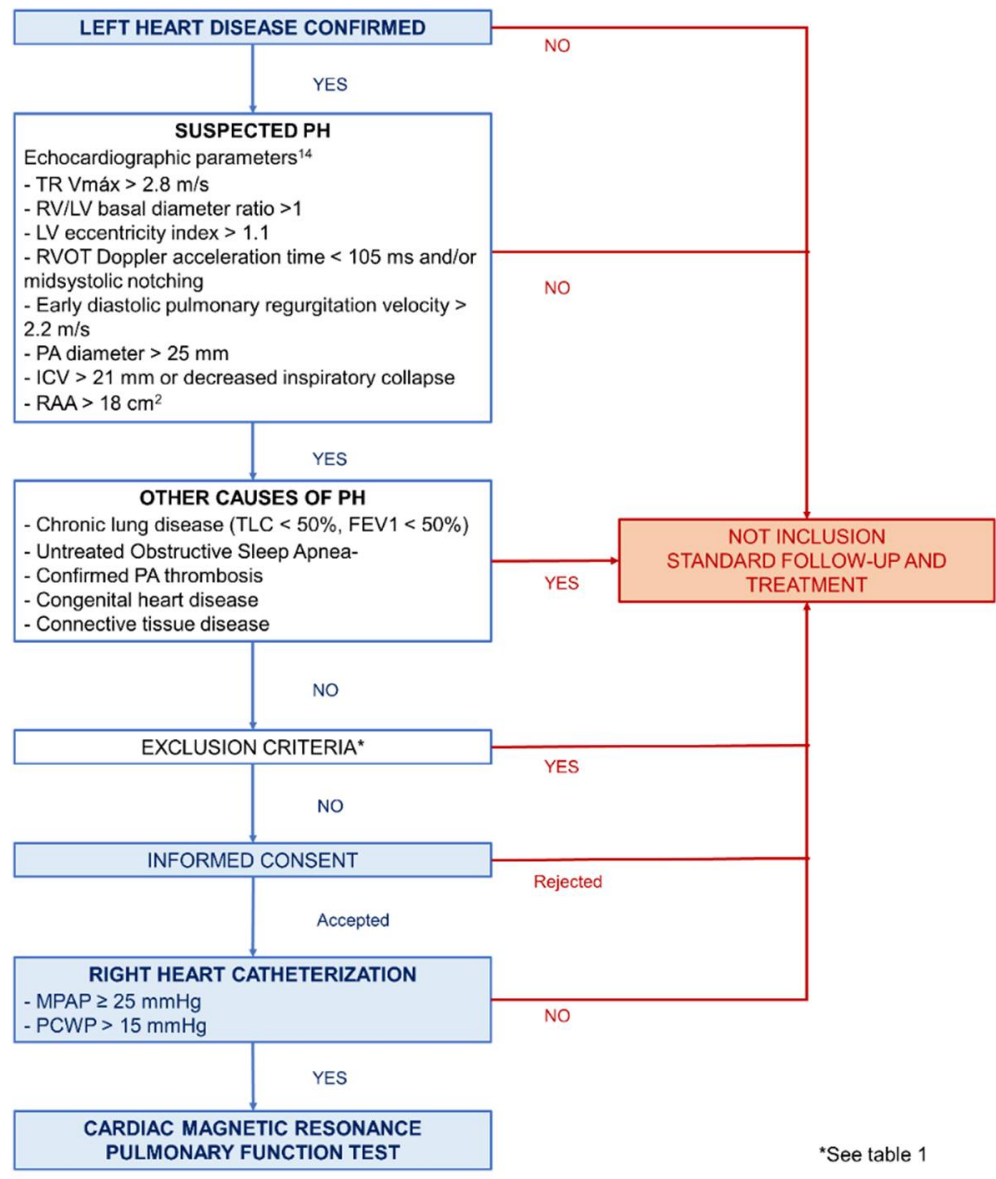

Figure 2. Patients' selection and study organization. Patients with symptomatic HF will be considered for the study if they have been diagnosed with left heart disease with an echocardiographic suspicion of $\mathrm{PH}$, not explained by other causes. Those patients meeting all inclusion criteria and no exclusion criteria (see Table 1) who have PH confirmed by RHC will be submitted to magnetic resonance imaging and a pulmonary function test. ICV: inferior cava vein; LV: left ventricle; MPAP: mean pulmonary artery pressure; PA: pulmonary artery; PCWP: pulmonary capillary wedge pressure; PH: pulmonary hypertension; RAA: right atrial area; RV: right ventricle; RVOT: right ventricle outflow tract; TLC: total lung capacity; FEV1: forced expiratory volume in first second; TR: tricuspid regurgitation.

\subsection{Sample Size and Statistical Analysis}

According to previous studies performed by our group, passive congestive $\mathrm{PH}$ is present in almost $75 \%$ of patients with chronic HF, whereas $25 \%$ are diagnosed with combined pre- and postcapillary PH [17].

To the best of our knowledge, no previous study has analyzed the differences between combined PH and isolated postcapillary PH by means of MRI. Therefore, our estimations are based on studies comparing precapillary $\mathrm{PH}$, basically PAH WHO group 1, and healthy controls without $\mathrm{PH}$. Considering the high number of different variables to analyze, as well as their diversity, we have accepted the largest calculated sample size with a $99 \%$ confidence interval. Assuming an $\alpha$-level of 0.01 and a bilateral $\beta$-level of 0.02 , our sample will require 13 patients with combined $\mathrm{PH}$ and 40 with postcapillary $\mathrm{PH}$ in order to detect significant differences $[1,18,19]$.

The normality of data distribution will be assessed by the Shapiro-Wilk test. Continuous variables will be expressed as mean \pm standard deviation if normally distributed; otherwise, they will be described as medians and interquartile ranges. Categorical variables will be expressed as percentages and compared using the Chi-squared test or Fisher's exact test. Continuous variables will be compared with Student's t-test or the Kruskal-Wallis rank test. Determinants of combined PH will be assessed with univariate logistic regression 
analysis. Independent predictors of combined PH development will be analysed with multivariate analysis using a backward stepwise selection. All variables with a $p$-value $<0.20$ will be included at first. At each step, the least significant variable will be removed from the model, until all variables reache a $p$-value $<0.20$. All tests will be two-sided and a $p$-value $<0.05$ will be considered statistically significant. All statistical analyses will be performed with STATA version 15.1 (Stata Corp LLC, TX, USA). Graphs will be designed using RStudio ggplot 2 (RStudio Team (2015), Integrated development for RStudio, Inc., Boston, MA, USA).

\subsection{Funding}

Funding for this study is supplied by the European Regional Development Fund and the Carlos III Research Institute through a grant of the Health Strategy Action (PI17/01569).

\section{Discussion}

Pulmonary hypertension due to HF is a marker of poor prognosis owing to a higher risk of morbidity and mortality $[1,3,4]$. Initially, PH due to HF is a passive consequence of high preloading conditions of the left ventricle and high PCWP. If maintained over time, chronically elevated pressures induce endothelial damage in the pulmonary vasculature, which starts a remodeling process characterized by intimal fibrosis, medial hypertrophy, and thickening of the adventitia $[4,20]$. This reactive response adds to the passive component of congestion, resulting in a combined pre- and postcapillary $\mathrm{PH}$, which occurs in up to $25 \%$ of the patients with advanced HF [17]. These structural changes trigger an increase in vascular stiffness and PVR, first functional with dynamic behavior as a result of vasoconstriction, which is reversible with vasodilators, but finally fixed and irreversible as a result of pulmonary vasculopathy. Thus, the pulmonary vascular bed becomes a high-pressure high-resistance system, increasing the risk of right ventricular failure. Therefore, fixed combined pre- and postcapillary PH is a marker of poorer prognosis and even a formal contraindication for heart transplantation [21].

Severity assessment of PH and PVR requires an invasive hemodynamic evaluation in order to identify the passive and the reactive component, as well as to determine whether the latter is reversible or fixed. It allows to determine cardiac output and PVR, as well as to analyze response to treatment. Thus, RHC remains necessary for the prognostic evaluation in patients with chronic HF. However, it has certain limitations, as it is an invasive procedure that often requires exposure to radiation. In this sense, CardioMEMS has proven to be a wireless device that allows ambulatory pulmonary artery pressure determination, providing information about volume status in HF patients and reducing HF hospitalizations. Nevertheless, it requires an RHC in order to implant a small microchip transvenously in the distal pulmonary artery, and is thus not exempt from complications [22]. For these reasons, the development of non-invasive tools allowing anatomical and functional evaluation of the right ventricle and pulmonary vasculature is desirable.

Echocardiography is the first method of choice in cases of suspected $\mathrm{PH}$, being an appropriate screening method. However, it is based on an estimation of pulmonary pressures, allowing neither an exact determination nor evaluation of capillary wedge pressures. Furthermore, it is limited by the complex anatomy of the right ventricle, thus relying on geometric assumptions in order to evaluate ventricular volumes and function.

MRI has become the reference diagnostic imaging tool for the assessment of the right ventricle and pulmonary circulation. MRI techniques allow accurate measures of right ventricular size, stroke volume, myocardial mass and ejection fraction, $4 \mathrm{D}-$ flow assessment of the pulmonary artery, tissue characterization of the right ventricle, and quantification of lung perfusion.

Four-dimensional flow MRI (time-resolved 3D phase contrast (PC)-MRI with 3D velocity encoding) is capable of non-invasively measuring complex 3D hemodynamic changes with full volumetric coverage of the right ventricle and pulmonary artery. Flow parameters can be subsequently evaluated in every region of interest. PC-MRI can be 
employed to assess cardiovascular hemodynamics and quantify blood flow velocities in the main pulmonary artery, right ventricle, and right ventricular outflow tract, and allows to obtain other advanced hemodynamic parameters: pulse-wave velocity (correlated with vessel wall elasticity), turbulent kinetic energy (TKE) (determines blood flow efficiency; the higher the TKE, the harder the heart has to work) [23], and wall shear stress (related to endothelial cell function and vascular remodeling). A recent 4D-flow MRI study reported that peak systolic velocity, peak flow, stroke volume, and wall shear stress at all locations were significantly lower in patients with PAH than in healthy subjects [10].

Delayed-enhancement imaging allows to identify focal myocardial abnormalities of myocardial fibrosis at the right ventricle insertion points, which directly correlates with the severity of $\mathrm{PH}$, and is a marker of poor prognosis [5].

T1 mapping sequences allow to identify diffuse myocardial abnormalities without the need for contrast. Increased T1 times in anterior and posterior septal insertion have been described in PAH patients, and T1 relaxation times have demonstrated a correlation with different markers of severity of the disease [8,9]. In addition, in HFpEF, T1 relaxation times have been shown to have a good correlation with pulmonary artery hemodynamics and prognosis [10].

All previously described parameters are associated with the severity of PAH [7-12]. However, no study has evaluated the prognostic relevance of MRI in patients with $\mathrm{PH}$ due to HF. The aim of our study is to assess structural and functional changes in pulmonary vasculature with this non-invasive imaging technique in order to identify combined preand postcapillary pulmonary hypertension, as well as to correlate these findings with the hemodynamic data.

Structural changes in the pulmonary vascular wall have been associated with a reduction in alveolar-capillary membrane diffusion, mainly in $\mathrm{PH}$ related to systemic sclerosis and idiopathic pulmonary fibrosis [24,25]. In patients with PAH, DLCO impairment has been associated with a worse functional class, and a DLCO $<43 \%$ has been shown to be an independent risk factor for death [11]. However, no relationship has been found between DLCO levels and hemodynamic parameters. Recently, Hoeper et al. [12] described an increase in 3-year mortality in patients with $\mathrm{PH}$ and HFpEF fraction who had a DLCO $<45 \%$, with otherwise normal pulmonary function. These findings were not associated with signs of pulmonary congestion, suggesting the presence of small-vessel vasculopathy affecting post-capillary venules instead of interstitial edema as the cause of low DLCO. Thus, our study will include a pulmonary functional assessment through DLCO determination in order to analyze its prognostic value in PH due to chronic HF.

\section{Limitations}

This work has the inherent disadvantage of being a single-center, nonrandomized study. However, we believe our results will be generalizable to other centers with a similar HF patient population. The principal limitations of MRI assessment are its elevated cost and long acquisition times, the interaction of metallic devices, and the risk of nephrogenic systemic fibrosis patients with impaired renal function after the use of gadolinium.

\section{Conclusions}

Despite technological advances, RHC continues to be necessary for prognostic evaluation in patients with chronic HF. This study will assess the feasibility of a non-invasive structural and functional evaluation of the pulmonary arterial vasculature in order to determine if there is a relationship with the degree and type of pulmonary hypertension diagnosed by hemodynamic criteria.

Author Contributions: Conceptualization, I.P., J.N., M.D.G.-C.C., J.S.d.J.B., A.R.C., F.A.Y., B.I. and J.F.D.J.; methodology—right heart catheterization, F.S.C.; methodology—cardiac magnetic resonance, V.S.S.; investigation, I.P., J.N., Z.B.-B., and P.C.P.; validation, J.N. and J.S.-G.; writing-original draft preparation, I.P. and J.N.; writing—review and editing, J.F.D.J.; supervision, B.I. and J.F.D.J.; 
funding acquisition, I.P. and J.F.D.J. All authors have read and agreed to the published version of the manuscript.

Funding: This research was funded by European Regional Development Fund and the Carlos III Research Institute through a grant of the Health Strategy Action (PI17/01569).

Institutional Review Board Statement: The study was conducted according to the guidelines of the Declaration of Helsinki, and approved by the Institutional Review Board of the University Hospital 12 de Octubre (protocol code 17/468 on 16 January 2018).

Informed Consent Statement: All subjects gave their informed consent for inclusion before they participated in the study.

Data Availability Statement: The data presented in this study are available on request from the corresponding author. The data are not publicly available due to privacy reasons.

Conflicts of Interest: The authors declare no conflict of interest. The funders had no role in the design of the study; in the collection, analyses, or interpretation of data; in the writing of the manuscript; or in the decision to publish the results.

\section{References}

1. Vachiery, J.-L.; Adir, Y.; Barberà, J.A.; Champion, H.C.; Coghlan, J.G.; Cottin, V.; De Marco, T.; Galiè, N.; Ghio, S.; Gibbs, J.S.R.; et al. Pulmonary Hypertension Due to Left Heart Diseases. J. Am. Coll. Cardiol. 2013, 62, D100-D108. [CrossRef] [PubMed]

2. Ghio, S.; Gavazzi, A.; Campana, C.; Inserra, C.; Klersy, C.; Sebastiani, R.; Arbustini, E.; Recusani, F.; Tavazzi, L. Independent and additive prognostic value of right ventricular systolic function and pulmonary artery pressure in patients with chronic heart failure. J. Am. Coll. Cardiol. 2001, 37, 183-188. [CrossRef]

3. Guazzi, M.; Naeije, R. Pulmonary Hypertension in Heart Failure. J. Am. Coll. Cardiol. 2017, 69, 1718-1734. [CrossRef] [PubMed]

4. Jiménez, J.D.; Conde, E.; Sánchez, V.; López-Ríos, F.; Gómez-Sánchez, M.A.; Escribano, P.; Sotelo, T.; De La Cámara, A.G.; Cortina, J.; De La Calzada, C.S. Pulmonary vascular remodeling in pulmonary hypertension due to chronic heart failure. Eur. J. Heart Fail. 2005, 7, 1011-1016.

5. Freed, B.H.; Collins, J.D.; François, C.J.; Barker, A.J.; Cuttica, M.J.; Chesler, N.C.; Markl, M.; Shah, S.J. MR and CT Imaging for the Evaluation of Pulmonary Hypertension. JACC Cardiovasc. Imaging 2016, 9, 715-732. [CrossRef] [PubMed]

6. Reiter, U.; Reiter, G.; Kovacs, G.; Adelsmayr, G.; Greiser, A.; Olschewski, H.; Fuchsjäger, M. Native myocardial T1 mapping in pulmonary hypertension: Correlations with cardiac function and hemodynamics. Eur. Radiol. 2017, 27, 157-166. [CrossRef] [PubMed]

7. Chen, Y.Y.; Yun, H.; Jin, H.; Kong, D.H.; Long, Y.L.; Fu, C.X.; Yang, S.; Zeng, M. Association of native T1 times with biventricular function and hemodynamics in precapillary pulmonary hypertension. Int. J. Cardiovasc. Imaging 2017, 33, 1179-1189. [CrossRef]

8. Nitsche, C.; Kammerlander, A.A.; Binder, C.; Duca, F.; Aschauer, S.; Koschutnik, M.; Snidat, A.; Beitzke, D.; Loewe, C.; Bonderman, D.; et al. Native T1 time of right ventricular insertion points by cardiac magnetic resonance: Relation with invasive haemodynamics and outcome in heart failure with preserved ejection fraction. Eur. Heart J. Cardiovasc. Imaging 2019, $21,683-691$. [CrossRef]

9. Swift, A.J.; Telfer, A.; Rajaram, S.; Condliffe, R.; Marshall, H.; Capener, D.; Hurdman, J.; Elliot, C.; Kiely, D.G.; Wild, J.M. Dynamic contrast-enhanced magnetic resonance imaging in patients with pulmonary arterial hypertension. Pulm. Circ. 2014, 4, 61-70. [CrossRef]

10. Barker, A.J.; Roldan-Alzate, A.; Entezari, P.; Shah, S.J.; Chesler, N.C.; Wieben, O.; Markl, M.; Francois, C.J. 4D Flow Assessment of Pulmonary Artery Flow and Wall Shear Stress in Adult Pulmonary Arterial Hypertension: Results from Two Institutions. Magn. Reson. Med. 2015, 73, 1904-1913. [CrossRef]

11. Chandra, S.; Shah, S.J.; Thenappan, T.; Archer, S.L.; Rich, S.; Gomberg-Maitland, M. Carbon monoxide diffusing capacity and mortality in pulmonary arterial hypertension. J. Heart Lung Transplant. 2010, 29, 181-187. [CrossRef]

12. Hoeper, M.M.; Meyer, K.; Rademacher, J.; Fuge, J.; Welte, T.; Olsson, K.M. Diffusion Capacity and Mortality in Patients with Pulmonary Hypertension Due to Heart Failure with Preserved Ejection Fraction. JACC Heart Fail. 2016, 4, 441-449. [CrossRef] [PubMed]

13. Ponikowski, P.; Voors, A.A.; Anker, S.D.; Bueno, H.; Cleland, J.; Coats, A.J.S.; Falk, V.; González-Juanatey, J.R.; Harjola, V.-P.; Jankowska, E.; et al. 2016 ESC GUIDELINES FOR THE DIAGNOSIS AND TREATMENT OF ACUTE AND CHRONIC HEART FAILURE. Russ. J. Cardiol. 2016, 37, 2129-2200.

14. Galiè, N.; Humbert, M.; Vachiery, J.-L.; Gibbs, S.; Lang, I.; Torbicki, A.; Simonneau, G.; Peacock, A.; Noordegraaf, A.V.; Beghetti, M.; et al. 2015 ESC/ERS Guidelines for the diagnosis and treatment of pulmonary hypertension. The Joint Task Force for the Diagnosis and Treatment of Pulmonary Hypertension of the European Society of Cardiology (ESC) and the European Respiratory Society (ERS). Eur. Respir. J. 2015, 46, 1855-1856. [CrossRef]

15. Houston, B.A.; Tedford, R.J. What We Talk About When We Talk About the Wedge Pressure. Circ. Heart Fail. 2017, 10, e004450. [CrossRef] [PubMed]

16. Simonneau, G.; Montani, D.; Celermajer, D.S.; Denton, C.P.; Gatzoulis, M.A.; Krowka, M.; Williams, P.G.; Souza, R. Haemodynamic definitions and updated clinical classification of pulmonary hypertension. Eur. Respir. J. 2019, 53, 1801913. [CrossRef] [PubMed] 
17. Garrido-Lestache, E.B.; Gómez-Sánchez, M.A.; de la Cruz, J.; Gonzalez-Trevilla, A.A.; Martín, M.T.V.; Cano, M.J.R.; Jiménez, J.F.D.; Subias, P.E.; López-Guarch, C.J.; Peiretti, M.A.C.; et al. Pulmonary Hypertension "Out of Proportion" in Patients who are Candidates for Heart Transplant: Does Acute Vasodilator Response to Sildenafil Predict Survival after Transplant? J. Pulmon. Resp. Med. 2013, S4, 003.

18. Jeong, H.J.; Vakil, P.; Sheehan, J.J.; Shah, S.J.; Cuttica, M.; Carr, J.C.; Carroll, T.J.; Davarpanah, A. Time Resolved MRA: Evaluation of Intrapulmonary Circulation Parameters in Pulmonary Arterial Hypertension. J. Magn. Reson. Imaging 2011, 33, $225-231$. [CrossRef]

19. Chäfer, M.; Kheyfets, V.O.; Schroeder, J.D.; Dunning, J.; Shandas, R.; Buckner, J.K.; Browning, J.; Hertzberg, J.; Hunter, K.S.; Fenster, B.E. Main Pulmonary Arterial Wall Shear Stress Correlates with Invasive Hemodynamics and Stiffness in Pulmonary Hypertension. Pulm. Circ. 2016, 6, 37-45. [CrossRef] [PubMed]

20. Delgado, J.F.; Jiménez, J.D. La circulación pulmonar en la insuficiencia cardiaca. Rev. Española Cardiol. 2010, 63, 334-345. [CrossRef]

21. Mehra, M.R.; Canter, C.E.; Hannan, M.M.; Semigran, M.J.; Uber, P.A.; Baran, D.A.; Danziger-Isakov, L.; Kirklin, J.K.; Kirk, R.; Kushwaha, S.S. The 2016 International Society for Heart LungTransplantation listing criteria for heart transplantation: A 10-year update. J. Heart Lung Transplant. 2016, 35, 1-23. [CrossRef] [PubMed]

22. Vanoli, E.; D’Elia, E.; La Rovere, M.T.; Gronda, E. Remote heart function monitoring: Role of the CardioMEMS HF System. J. Cardiovasc. Med. 2016, 17, 518-523. [CrossRef] [PubMed]

23. Zajac, J.; Eriksson, J.; Dyverfeldt, P.; Bolger, A.F.; Ebbers, T.; Carlhäll, C.-J. Turbulent kinetic energy in normal and myopathic left ventricles. J. Magn. Reson. Imaging 2015, 41, 1021-1029. [CrossRef] [PubMed]

24. Hamada, K.; Nagai, S.; Tanaka, S.; Handa, T.; Shigematsu, M.; Nagao, T.; Mishima, M.; Kitaichi, M.; Izumi, T. Significance of Pulmonary Arterial Pressure and Diffusion Capacity of the Lung as Prognosticator in Patients with Idiopathic Pulmonary Fibrosis. Chest 2007, 131, 650-656. [CrossRef] [PubMed]

25. Kawut, S.M.; Taichman, D.B.; Archer-Chicko, C.L.; Palevsky, H.I.; Kimmel, S.E. Hemodynamics and Survival in Patients with Pulmonary Arterial Hypertension Related to Systemic Sclerosis*. Chest 2003, 123, 344-350. [CrossRef] 